\title{
Measurement and Prediction of Thermal Conductivity of Volcanic Basalt Rocks from Warsak Area
}

\author{
Aurang Zeb, ${ }^{1}$ Muhammad Abid $\mathbb{D}^{2}{ }^{2}$ Misbah Aurang Zeb, ${ }^{3}$ Muhammad Omer Qureshi, ${ }^{1}$ \\ Usman Younas, ${ }^{1}$ and Irem Batool ${ }^{4}$ \\ ${ }^{1}$ Department of Applied Physics, Federal Urdu University of Arts Science and Technology, Islamabad Sector G-7/1, \\ Islamabad 44000, Pakistan \\ ${ }^{2}$ Department of Mechanical Engineering, COMSATS University Islamabad, Wah Campus, GT Road, Quaid Avenue, Wah Cantt, \\ Rawalpindi 47040, Pakistan \\ ${ }^{3}$ Department of Physics, COMSATS University Islamabad, Islamabad Campus, Park Road, Islamabad 45550, Pakistan \\ ${ }^{4}$ Department of Management Sciences, COMSATS University Islamabad, Sahiwal Campus, Off GT Road, \\ Sahiwal 57000, Pakistan \\ Correspondence should be addressed to Muhammad Abid; m.abid@ciitwah.edu.pk
}

Received 9 February 2020; Revised 1 May 2020; Accepted 7 August 2020; Published 24 August 2020

Academic Editor: Raul Arenal

Copyright (C) 2020 Aurang Zeb et al. This is an open access article distributed under the Creative Commons Attribution License, which permits unrestricted use, distribution, and reproduction in any medium, provided the original work is properly cited.

\begin{abstract}
Accurate values of thermal properties of rocks are needed for a number of engineering applications starting from heat losses in buildings to underground geothermal modeling. Igneous rocks are one of the major constituents of the Earth's crust and are formed by the crystallization and solidification of molten magma. In this work, the thermal transport properties of porous igneous basalt rocks are measured using Transient Plane Source (TPS) technique under ambient conditions with air as saturant in pore spaces. Data are presented for fifteen samples of volcanic basalt rocks having different porosity values ranging from $0.267 \%$ to $9.432 \%$ by volume, taken from the place of Warsak near Peshawar city, located in the north of Pakistan. The porosity and density parameters are measured using the American Society of Testing and Materials (ASTM) standards. The mineral compositions of the samples are analyzed by X-ray fluorescence (XRF) technique. The specific gravity is predicted using the chemical composition of basalts and is compared with the experimental results. The thermal conductivity and thermal diffusivity values of the measured samples are also predicted using the mixing law and empirical models and results are compared with the measured data. Results show that the thermal conductivity of the studies of basalt samples decreases with the increase in porosity values, whereas no significant change has been observed in the thermal diffusivity data. Measured data are significant for geothermal modeling and in predicting heat losses in buildings wherever basalt rocks are used.
\end{abstract}

\section{Introduction}

Knowledge of thermal transport properties of rocks has been a subject of great interest for scientists and engineers for estimation of exact heat transfer in rocks during the drilling process at oil and gas extraction plants. Accurate values of thermal properties of rocks are needed for geothermal modeling and underground energy storage [1-4]. Rocks are considered as poor heat conducting solids and their thermal conductivities are based mainly on phononic (lattice conductivity) contribution. Zimmerman reported the existence of several correlations among thermal conductivity, density, and porosity $[5,6]$. The effects of a number of physical properties on lattice thermal conductivity of several dry sandstone samples were investigated by Anand in 1973 [7-9].

Igneous rocks are the major constituent of the Earth's crust and are formed by the crystallization and solidification of molten magma. On the basis of grain size, igneous rocks are classified into two groups: (1) when magma or lava cools above the surface of the Earth, extrusive or volcanic igneous (fine-grained) rocks are formed, and (2) when magma cools 
below the surface of the Earth, intrusive or plutonic (coarsegrained) rocks are formed $[10,11]$. Depending on chemical composition, igneous rocks are classified into four groups, namely, ultramafic $\left(\mathrm{SiO}_{2}<45 \%\right)$, mafic $\left(\mathrm{SiO}_{2} 45-52 \%\right)$, intermediate $\left(\mathrm{SiO}_{2} 53-65 \%\right)$, and felsic $\left(\mathrm{SiO}_{2}>65 \%\right)$. Basalt rocks are considered as the most common volcanic rocks on the Earth and form a key component of ocean crust. Basalt is a fine-grained dark-colored rock mostly used in construction in the form of building blocks and as groundwork for flooring and on roads because it impedes moisture diffusion due to its low porosity values $[12,13]$. The samples under study are of basalt and they belong to the mafic group of igneous rocks which contains about $45-52 \%$ of silica content.

To measure the thermal transport properties of rocks, a number of transient and steady-state techniques are used; however, due to long measuring time, steady-state methods are not preferred for moist/saturated materials. On the other hand, transient techniques are preferred for their short measuring time and simultaneous measurements of both thermal conductivity and thermal diffusivity. Bouguerra et al. used the Transient Plane Source (TPS) technique to measure thermal conductivity of solid aggregates of building materials and performed both experimental and theoretical work concerning the evaluation of thermal conductivity, thermal diffusivity, and heat capacity of wood composites, using again the well-known TPS technique [14, 15]. The work of Gruescu et al. was concerned with the determination of effective thermal conductivity of porous rocks or rock-like composites composed by multiple solid constituents in partially saturated conditions [16]. Gong et al. prepared porous mullite ceramics from an industrial grade mullite powder by foaming and starch consolidation, measured their thermal conductivity using TPS technique, and discussed the relationship between thermal conductivity and porosity in detail [17].

In this work, igneous basalt rock samples are collected from a place called "Warsak" in the north of Pakistan. The area of Warsak is situated about $30 \mathrm{~km}$ from Peshawar city at geological location of $34^{\circ} 6^{\prime}-34^{\circ} 14^{\prime} \mathrm{N}$ latitude and $71^{\circ} 20^{\prime}-71^{\circ} 26^{\prime}$ E longitude $[18,19]$. A geological survey and map of the Warsak area have already been discussed in detail by many authors [18-21]. For instance, geological map of the studied area and petrography of the rocks have been discussed in detail by Ahmad et al. Continental magmatism related to late Paleozoic and Mesozoic rifting in Warsak area and the confirmation of the basaltic nature of the studied area rocks have been given by Qasim Jan and Karim [22].

As a measurement method, Transient Plane Source (TPS) technique is used for the thermophysical property measurements of the rock samples as a function of porosity. Existing theoretical and mixing law models are used to predict the effective thermal conductivities of basalt rock samples and results are compared with the experimental data. Results obtained through this study can be used as imperative input data for geothermal simulations and for predicting heat transfer rate in buildings made of basalt rocks.

\section{Effective Thermal Conductivity Prediction Models}

The effective thermal conductivity $\left(\lambda_{\mathrm{e}}\right)$ of multiphase porous media depends on the thermal conductivities and the volume fractions of the constituting phases. Therefore, the effective thermal conductivity of the system is the function of the individual thermal conductivities of the solid matrix $\left(\lambda_{\mathrm{s}}\right)$, the thermal conductivity of the saturating fluid $\left(\lambda_{\mathrm{f}}\right)$, and porosity $(\phi)$ of the packed bed; that is, $\lambda_{\mathrm{e}}=\lambda_{\mathrm{e}}\left(\lambda_{\mathrm{s}}, \lambda_{\mathrm{f}}, \phi\right)$. In general, three basic types of models are used for the prediction of the effective thermal conductivity, namely, mixing law models, empirical models, and theoretical models [23].

Following are a few well-known thermal conductivity models used to predict the thermal conductivity of porous materials:

$$
\begin{aligned}
& \lambda_{\mathrm{e}}=\phi \lambda_{\mathrm{f}}+(1-\phi) \lambda_{\mathrm{s}} \text { parellel model, } \\
& \lambda_{\mathrm{e}}=\left[\frac{\phi}{\lambda_{\mathrm{f}}}+\frac{(1-\phi)}{\lambda_{\mathrm{s}}}\right]^{-1} \text { series model. }
\end{aligned}
$$

Equations (1) and (2) are also called Wiener's upper and lower bounds, respectively.

Hashin and Shtrikman gave another set of bounds on thermal conductivity of two-phase system which is more precise/narrow as compared to Wiener's bounds [24]:

$$
\begin{gathered}
\lambda_{\mathrm{e}}=\lambda_{\mathrm{s}}+\frac{3 \lambda_{\mathrm{s}}\left(\lambda_{\mathrm{f}}-\lambda_{\mathrm{s}}\right) \phi}{3 \lambda_{\mathrm{s}}+\left(\lambda_{\mathrm{f}}-\lambda_{\mathrm{s}}\right)(1-\phi)}, \\
\lambda_{\mathrm{e}}=\lambda_{\mathrm{f}}+\frac{3 \lambda_{\mathrm{f}}\left(\lambda_{\mathrm{s}}-\lambda_{\mathrm{f}}\right)(1-\phi)}{3 \lambda_{\mathrm{f}}+\left(\lambda_{\mathrm{s}}-\lambda_{\mathrm{f}}\right) \phi} .
\end{gathered}
$$

Another mixing law model is geometric mean model and is given as follows [25]:

$$
\lambda_{\mathrm{e}}=\lambda_{\mathrm{s}}\left[\frac{\lambda_{\mathrm{f}}}{\lambda_{\mathrm{s}}}\right]^{\phi} .
$$

Extended Maxwell model was developed on strong physical backgrounds by Beck [26]:

$$
\lambda_{\mathrm{e}}=\lambda_{\mathrm{s}}\left[\begin{array}{l}
\left(\frac{2 \lambda_{\mathrm{s}}}{\lambda_{\mathrm{f}}}+1\right)-2 \phi\left(\frac{\lambda_{\mathrm{s}}}{\lambda_{\mathrm{f}}}-1\right) \\
\left(\frac{2 \lambda_{\mathrm{s}}}{\lambda_{\mathrm{f}}}+1\right)+\phi\left(\frac{\lambda_{\mathrm{s}}}{\lambda_{\mathrm{f}}}-1\right)
\end{array}\right] .
$$

Asaad's equation is very similar to the WGM model [27]:

$$
\lambda_{\mathrm{e}}=\lambda_{\mathrm{s}}\left[\frac{\lambda_{\mathrm{f}}}{\lambda_{\mathrm{s}}}\right]^{c \phi}
$$

where $c$ is the empirical exponent which is equal to 1 for low porosity samples [28].

Kumar and Chaudhary presented a model for the prediction of effective thermal conductivity $[29,30]$ : 


$$
\lambda_{\mathrm{e}}=(1-\phi) \lambda_{\mathrm{H}}+\phi \lambda_{\mathrm{L}}-\Psi\left(\frac{\lambda_{\mathrm{s}}}{\lambda_{\mathrm{f}}}\right)^{1 / 3},
$$

where $\quad \lambda_{\mathrm{H}}=\lambda_{\mathrm{s}} \mathrm{e}^{\beta \phi}, \quad \lambda_{\mathrm{L}}=\lambda_{\mathrm{s}} \mathrm{e}^{-\beta(1-\phi)} \quad$ for $\quad \lambda_{\mathrm{L}}>\lambda_{\mathrm{f}}$, $\beta=\left[\left(\lambda_{\mathrm{f}} / \lambda_{\mathrm{s}}\right)-1\right]$, and $\Psi$ is an adjustable parameter.

For porous consolidated materials, Pande et al. proposed an empirical model of the following form [31]:

$$
\lambda_{\mathrm{e}}=\mathrm{F}(0.6132)\left(\lambda_{\mathrm{s}} \lambda_{\mathrm{f}}\right)^{1 / 2}\left(1+3.844 \xi_{\mathrm{s}}^{2 / 3}\right), \text { for } \xi_{\mathrm{s}}>0 \text {, }
$$

where $\xi_{\mathrm{s}}$ is the volume fraction of solid phase and $\mathrm{F}$ is an empirical coefficient.

Aurangzeb et al. model for the prediction of thermal conductivity of porous consolidated materials is stated as [32]

$$
\frac{1}{\lambda_{\mathrm{e}}}=\left[\frac{1}{\lambda_{\mathrm{s}}}+\frac{m \phi}{\lambda_{\mathrm{f}}}\right]
$$

where $m$ is an empirical coefficient that can be determined by knowing experimental values of effective thermal conductivities.

Exponential Decay Trial (EDT) can also be applied to predict the thermal conductivity of consolidated porous media at room temperature $(303 \mathrm{~K})$ and normal pressure, as given as follows:

$$
\lambda_{\mathrm{e}}=\lambda_{\mathrm{s}} e^{-z \phi\left(\lambda_{\mathrm{s}} / \lambda_{\mathrm{f}}\right)}
$$

where $z$ is the empirical exponent [1]. Another point to be noted here is that all the empirical constants mentioned above are calculated by least-squares method.

\section{Experimental Setup}

Transient Plane Source (TPS), also known as Gustafsson's probe, is used for the measurement of thermophysical properties of a wide variety of isotropic and anisotropic materials including solids, pastes, and powders [14, 15, 33]. The sensor can be used for the measurements of thermal conductivity ranging from $0.005 \mathrm{Wm}-1 \mathrm{~K}-1$ to $500 \mathrm{Wm}-1 \mathrm{~K}-1$ according to ISO 22007-2 standards [34]. It consists of a $10 \mu \mathrm{m}$ thick plane spiral-shaped thermoelectric element made of pure nickel having a diameter of $20 \mathrm{~mm}$ deposited between two Kapton foils. Kapton foil ( $25 \mu \mathrm{m}$ thick) is used to ensure the electrical insulation and mechanical strength of the sensor. TPS sensor makes a Wheatstone bridge circuit and works simultaneously as a heater and thermometer. Basalt rock samples were prepared in the form of a disk having a diameter of $45 \mathrm{~mm}$ and thickness $25 \mathrm{~mm}$. The samples were dried at $105 \pm 2^{\circ} \mathrm{C}$ in furnace (Heraeus M110) for 24 hours, cooled down for half an hour, and put into desiccators to avoid moisture diffusion. To perform a measurement run, the sensor is sandwiched between two sample halves as shown in Figure 1(a). In addition, to minimize the contact resistance, surfaces of the samples were flattened as much as possible and sample halves were pressed with the help of a clamp or by putting additional weight over the samples.
During measurements, a constant electric current is passed through the sensor which increases the temperature of the sensor. In this work, we have used HP-6633A system power supply for current and HP3478A DMM for the voltage measurements across the bridge circuit, while both have interfaced with computer. During measurements, a current of $\approx 200 \mathrm{~mA}$ is applied to the sensor for a time interval of $120 \mathrm{~s}$. The heat generated due to Joule heating effect dissipates into the sample on both sides of the sensor homogeneously. The temperature rise $(\approx 2 \mathrm{~K}$ for basalt rocks) of the sensor depends on the thermal properties of the measured sample. By recording temperature versus time response of the sensor, the thermal conductivity and thermal diffusivity of the material can be measured, whereas the specific heat capacity of the sample can be calculated by using equation (11). One has

$$
c_{\mathrm{p}}=\frac{\lambda}{\rho \alpha}
$$

where $\rho$ is the density and $\alpha$ is the thermal diffusivity of the sample.

The theory of the TPS sensor assumes that the sensor is kept in an infinite medium (sample) and the diffused heat is not crossing the boundaries of the measured sample. Therefore, measurement time is chosen in such a way that the generated heat penetrates into the sample but does not leave the sample boundaries. About 200 data points are collected from each measurement run. Some of the initial data points are neglected to eliminate the effect of contact resistance. As far as measurement errors of this technique are concerned, the standard deviations in the measurements of thermal conductivity, thermal diffusivity, and specific heat capacity are $5 \%, 7 \%$, and $10 \%$, respectively [33-36].

\section{Sample Characterization}

To understand the chemistry of the samples under consideration, chemical composition is analyzed by XRF technique with the collaboration of Khan Research Laboratories, Kahuta, Islamabad, and is given in Table 1. Since silica content of the studied rocks lies between 42 and 52\% and according to the total alkali-silica (TAS) diagram, the $\left(\mathrm{Na}_{2} \mathrm{O}+\mathrm{K}_{2} \mathrm{O}\right)$ percentage lies within $5 \%$; therefore, basalt nature of the samples is confirmed [37].

Porosity, density, and specific gravity are grouped as density-related properties of the rocks. These properties depend upon mineral composition and structure of rocks. All of these quantities are measured using ASTM-D6473-15 standards [38] and are given in Table 2. Specific gravity is also determined using Felsic-Mafic index [39] as

$$
\text { specific gravity }=2.643+0.444 e^{-F / 4}
$$

where $F=\mathrm{SiO}_{2}+\mathrm{Na}_{2} \mathrm{O}+\mathrm{K}_{2} \mathrm{O} / \mathrm{FeO}+\mathrm{Fe}_{2} \mathrm{O}_{3}+\mathrm{CaO}+\mathrm{MgO}$ is known as Felsic-Mafic index.

From Table 2, it can be seen that porosity of the samples ranges from 0.00267 to 0.09432 . It can also be observed that percentage deviation of predicted specific gravity and its 


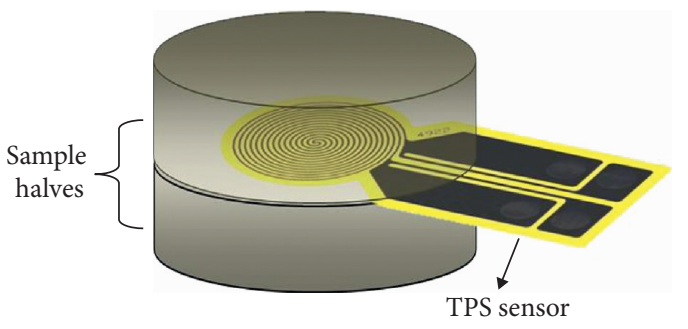

(a)

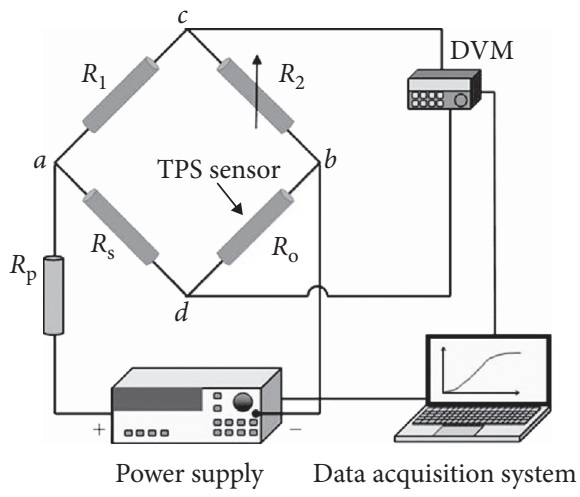

(b)

Figure 1: Experimental setup. (a) Transient Plane Source sensor sandwiched between two sample halves. (b) Circuit diagram with the data acquisition system.

TABle 1: Chemical composition of basalt rocks.

\begin{tabular}{lccccccccccc}
\hline Sample number & $\mathrm{SiO}_{2}$ & $\mathrm{TiO}_{2}$ & $\mathrm{Al}_{2} \mathrm{O}_{3}$ & $\mathrm{Fe}_{2} \mathrm{O}_{3}$ & $\mathrm{FeO}$ & $\mathrm{MnO}$ & $\mathrm{MgO}$ & $\mathrm{CaO}$ & $\mathrm{Na}_{2} \mathrm{O}$ & $\mathrm{K}_{2} \mathrm{O}$ & $\mathrm{P}_{2} \mathrm{O}_{5}$ \\
\hline BS-01 & 45.21 & 4.72 & 13.48 & 2.79 & 11.41 & 0.20 & 07.90 & 07.84 & 3.50 & 1.45 \\
BS-02 & 47.10 & 2.02 & 13.78 & 2.61 & 10.68 & 0.20 & 06.76 & 11.20 & 2.57 & 0.87 & 0.21 \\
BS-03 & 51.47 & 2.18 & 14.04 & 2.61 & 10.71 & 0.17 & 05.71 & 10.51 & 1.95 & 0.53 & 0.11 \\
BS-04 & 45.37 & 5.72 & 13.36 & 2.79 & 11.45 & 0.20 & 05.85 & 10.62 & 2.94 & 0.89 & 0.80 \\
BS-05 & 45.79 & 5.13 & 12.86 & 3.02 & 12.36 & 0.18 & 06.12 & 09.54 & 3.04 & 1.53 & 0.44 \\
BS-06 & 44.54 & 3.55 & 13.59 & 2.28 & 09.34 & 0.14 & 10.95 & 12.13 & 2.14 & 0.97 \\
BS-07 & 50.12 & 2.69 & 12.98 & 3.06 & 15.55 & 0.22 & 04.88 & 09.71 & 2.40 & 1.10 & 0.37 \\
BS-08 & 47.45 & 4.19 & 10.66 & 2.72 & 11.17 & 0.12 & 10.56 & 09.56 & 2.14 & 0.99 \\
BS-09 & 45.88 & 2.55 & 16.18 & 1.96 & 08.02 & 0.17 & 07.18 & 10.88 & 3.71 & 1.90 \\
BS-10 & 47.17 & 2.99 & 16.73 & 2.74 & 11.23 & 0.15 & 05.61 & 08.94 & 2.65 & 1.39 \\
BS-11 & 51.95 & 3.64 & 11.86 & 1.50 & 06.13 & 0.06 & 08.35 & 12.25 & 3.71 & 0.50 \\
BS-12 & 46.81 & 4.72 & 13.61 & 2.67 & 10.95 & 0.17 & 07.04 & 07.77 & 4.86 & 0.87 \\
BS-13 & 45.88 & 4.34 & 15.07 & 2.12 & 08.68 & 0.19 & 08.14 & 08.40 & 5.85 & 0.88 \\
BS-14 & 43.63 & 3.77 & 14.41 & 2.96 & 12.13 & 0.22 & 08.77 & 08.45 & 2.95 & 1.33 \\
BS-15 & 48.18 & 3.75 & 13.72 & 2.65 & 10.85 & 0.18 & 06.93 & 09.10 & 2.76 & 1.38 \\
\hline
\end{tabular}

TABLE 2: Density-related properties of basalt rocks.

\begin{tabular}{|c|c|c|c|c|c|}
\hline Sample number & Fractional porosity & Bulk density $\left(\mathrm{gm} / \mathrm{cm}^{3}\right)$ & $\begin{array}{l}\text { Specific gravity by } \\
\text { ASTM standards }\end{array}$ & $\begin{array}{l}\text { Specific gravity by } \\
\text { Felsic-Mafic index }\end{array}$ & Percentage deviation \\
\hline BS-01 & 0.0027 & 2.712 & 2.717 & 2.935 & 8.171 \\
\hline BS-02 & 0.0034 & 2.713 & 2.718 & 2.939 & 7.984 \\
\hline BS-03 & 0.0059 & 2.695 & 2.700 & 2.924 & 8.926 \\
\hline BS-04 & 0.0063 & 2.692 & 2.697 & 2.940 & 9.344 \\
\hline BS-05 & 0.0079 & 2.687 & 2.692 & 2.939 & 8.618 \\
\hline BS-06 & 0.0083 & 2.702 & 2.707 & 2.958 & 8.106 \\
\hline BS-07 & 0.0114 & 2.636 & 2.641 & 2.928 & 10.45 \\
\hline BS-08 & 0.0124 & 2.664 & 2.670 & 2.950 & 10.48 \\
\hline BS-09 & 0.0137 & 2.677 & 2.682 & 2.924 & 9.582 \\
\hline BS-10 & 0.0188 & 2.681 & 2.686 & 2.926 & 9.010 \\
\hline BS-11 & 0.0192 & 2.583 & 2.588 & 2.913 & 12.94 \\
\hline BS-12 & 0.0457 & 2.566 & 2.571 & 2.923 & 13.30 \\
\hline BS-13 & 0.0522 & 2.596 & 2.601 & 2.917 & 13.72 \\
\hline BS-14 & 0.0872 & 2.578 & 2.583 & 2.949 & 13.82 \\
\hline BS-15 & 0.0943 & 2.583 & 2.589 & 2.928 & 13.01 \\
\hline
\end{tabular}

experimentally measured values is up to $10 \%$ which is in agreement with the theory [40].

\section{Results}

Thermal transport properties of samples are measured experimentally using TPS technique (also known as Gustafsson's probe [33]) at room temperature $(303 \pm 2 \mathrm{~K})$ and 
TABLE 3: Thermal transport properties of basalt rocks along with standard deviations (SD).

\begin{tabular}{|c|c|c|c|c|c|c|c|}
\hline $\begin{array}{l}\text { Sample } \\
\text { number }\end{array}$ & $\begin{array}{l}\text { Porosity } \\
\quad(\phi)\end{array}$ & $\frac{\lambda_{\exp }}{\left(\mathrm{Wm}^{-1} \cdot \mathrm{K}^{-1}\right)}$ & $\begin{array}{l}\text { Standard } \\
\text { deviation }\end{array}$ & $a\left(\mathrm{~mm}^{2} \cdot \mathrm{s}^{-1}\right)$ & $\begin{array}{l}\text { Standard } \\
\text { deviation }\end{array}$ & $\begin{array}{c}\rho c_{\mathrm{p}} \\
\left(\mathrm{MJm}^{-3} \cdot \mathrm{K}^{-1}\right)\end{array}$ & $\begin{array}{l}\text { Standard } \\
\text { deviation }\end{array}$ \\
\hline BS-01 & 0.00267 & 3.024 & 0.049 & 1.190 & 0.080 & 2.541 & 0.139 \\
\hline BS-02 & 0.00341 & 3.014 & 0.029 & 1.223 & 0.040 & 2.464 & 0.061 \\
\hline BS-03 & 0.00586 & 3.060 & 0.036 & 1.250 & 0.058 & 2.448 & 0.082 \\
\hline BS-04 & 0.00633 & 2.481 & 0.032 & 0.925 & 0.050 & 2.682 & 0.137 \\
\hline BS-05 & 0.00787 & 2.626 & 0.039 & 1.048 & 0.063 & 2.506 & 0.118 \\
\hline BS-06 & 0.00827 & 2.985 & 0.039 & 1.125 & 0.057 & 2.653 & 0.079 \\
\hline BS-07 & 0.01137 & 2.196 & 0.021 & 0.922 & 0.041 & 2.382 & 0.059 \\
\hline BS-08 & 0.01242 & 2.074 & 0.012 & 0.864 & 0.037 & 2.400 & 0.083 \\
\hline BS-09 & 0.01373 & 2.772 & 0.049 & 1.043 & 0.030 & 2.658 & 0.044 \\
\hline BS-10 & 0.01878 & 2.465 & 0.038 & 1.012 & 0.056 & 2.435 & 0.106 \\
\hline BS-11 & 0.01917 & 2.374 & 0.017 & 0.965 & 0.044 & 2.460 & 0.094 \\
\hline BS-12 & 0.04569 & 2.195 & 0.010 & 0.867 & 0.027 & 2.532 & 0.073 \\
\hline BS-13 & 0.05221 & 2.542 & 0.035 & 1.017 & 0.047 & 2.500 & 0.081 \\
\hline BS-14 & 0.08724 & 2.254 & 0.018 & 0.964 & 0.024 & 2.338 & 0.046 \\
\hline BS-15 & 0.09432 & 2.003 & 0.040 & 0.834 & 0.054 & 2.402 & 0.126 \\
\hline
\end{tabular}

normal pressure using air as saturant in pore spaces. Obtained experimental results are given in Table 3. The thermal conductivity and thermal diffusivity values are obtained through experiments while volumetric heat capacity is calculated using equation (12).

Before applying mixing law and empirical models, the data is tested using thermal conductivity bounds as discussed in Section 2. To apply these bounds, the values of $\lambda_{\mathrm{f}}$ and $\lambda_{\mathrm{s}}$ are taken as $0.026 \mathrm{Wm}^{-1} \cdot \mathrm{K}^{-1}$ and $3.5 \mathrm{Wm}^{-1} \cdot \mathrm{K}^{-1}$, respectively. It is to be noted that the value of $\lambda_{\mathrm{s}}$ is calculated by opting for the method discussed by Aurangzeb et al. [1]. The upper and lower bound values of Wiener's and H-S bounds and values obtained through geometric mean model and Maxwell's model are given in Table 4.

Results show that the data lie well within the bounds that prove the authenticity of the obtained experimental data. After applying bounds, the thermal conductivity is also predicted using WGM model and Extended Maxwell model using equations (5) and (6), respectively. The results of Table 4 are plotted in Figure 2. Experimental thermal conductivity $\left(\lambda_{\text {exp }}\right)$ data and the effective thermal conductivity $\left(\lambda_{\mathrm{e}}\right)$ values predicted through various mixing law models are compared in Figure 2.

Experimental results are fitted nonlinearly through an allometric function as given as follows:

$$
\lambda_{\exp }=1.67 \times \phi^{-0.098},
$$

whereas the constant value 1.67 represents the thermal conductivity value of the basalt sample when fractional porosity approached a value of 1 , and the power tem "- 0.098 " is a scaling exponent representing proportional change (decrease in this case) in the thermal conductivity with respect to the change (increase in this case) in fractional porosity.

For the application of Asaad's model (equation (7)), Veerendra and Chaudhary model (equation (8)), Pande and Chaudhary model (equation (9)), Zeb et al. model (equation (10)), and EDT model (equation (11)) for thermal conductivity prediction, we used the value of thermal conductivity of fluid phase $\left(\lambda_{\mathrm{f}}\right)$ as $0.026 \mathrm{Wm}^{-1} \cdot \mathrm{K}^{-1}$ because air acts as fluid in pore spaces. The value of thermal conductivity of solid phase $\left(\lambda_{\mathrm{s}}\right)$ is calculated using the method described by Zeb et al. (2007). As mentioned earlier, the value of solid matrix thermal conductivity is calculated to be $\lambda_{\mathrm{s}}=3.5 \mathrm{Wm} \mathrm{Wm}^{-1} \cdot \mathrm{K}^{-1}$.

\section{Discussion}

Basalt nature of the rock is clearly confirmed by the higher silica contents $\left(42 \%<\mathrm{SiO}_{2}<52 \%\right)$ and less than $5 \%$ value of $\left(\mathrm{Na}_{2} \mathrm{O}+\mathrm{K}_{2} \mathrm{O}\right)$ chemicals within the samples as per TAS diagram. While $\mathrm{SiO}_{2}$ is the major mineral portion in the studied samples, for that reason we checked the dependency of thermal conductivity of the samples on silica contents. Figure 3 shows experimental results on basalt samples representing the dependence of thermal conductivity on silica contents within the samples. Surprisingly, we found no regular dependency of thermal conductivity within the observed range of silica contents in the studied samples. Thermal conductivity is bounded between 2 and $3 \mathrm{Wm}^{-1} \cdot \mathrm{K}^{-1}$ and all the values are randomly oriented showing no correlation within the studies samples.

Experimental results on the thermophysical properties as shown in Figure 2 represent that the thermal conductivity of the basalt samples ranges from 2.003 to $3.060 \mathrm{Wm}^{-1} \cdot \mathrm{K}^{-1}$ and thermal diffusivity ranges from 0.825 to $1.250 \mathrm{~mm}^{2} \cdot \mathrm{s}^{-1}$, whereas volumetric heat capacity ranges from 2.338 to $2.682 \mathrm{MJm}^{-3} \cdot \mathrm{K}^{-1}$. Results show that the thermal conductivity tends to decrease with the increase in porosity; however, no clear dependence on porosity can be observed from the thermal diffusivity data. In this work, we considered only dry samples during experimentation and expected that pore spaces are filled with dry air, consequently leading to the assumption that higher porosity means increased volume of air within the sample. It is obvious from the fact that as air being low thermal conductive medium $\left(\lambda_{\text {air }}=0.026 \mathrm{Wm}^{-1} \cdot \mathrm{K}^{-1}\right)$ replaces the higher thermal conductivity minerals, the overall bulk thermal conductivity of the sample decreases. The decrease in thermal conductivity 
TABLE 4: Fractional porosity, experimental thermal conductivity, and effective thermal conductivity obtained after using upper and lower thermal conductivity bounds.

\begin{tabular}{|c|c|c|c|c|c|c|c|c|}
\hline \multirow{2}{*}{ Sample number } & \multirow{2}{*}{ Fractional porosity } & \multirow{2}{*}{$\lambda_{\exp }\left(\mathrm{Wm}^{-1} \cdot \mathrm{K}^{-1}\right)$} & \multicolumn{2}{|c|}{ Wiener's bounds } & \multicolumn{2}{|c|}{ H-S bounds } & \multirow{2}{*}{$\begin{array}{l}\text { WGM model } \\
\text { Equation (5) }\end{array}$} & \multirow{2}{*}{$\begin{array}{c}\text { Maxwell mode } \\
\text { Equation (6) }\end{array}$} \\
\hline & & & Equation (1) & Equation (2) & Equation (3) & Equation (4) & & \\
\hline BS-01 & 0.00267 & 3.024 & 3.491 & 2.580 & 3.486 & 3.123 & 3.455 & 3.486 \\
\hline BS- 02 & 0.00341 & 3.014 & 3.488 & 2.405 & 3.482 & 3.032 & 3.442 & 3.482 \\
\hline BS-03 & 0.00586 & 3.060 & 3.480 & 1.963 & 3.470 & 2.765 & 3.401 & 3.470 \\
\hline BS-04 & 0.00633 & 2.481 & 3.478 & 1.897 & 3.467 & 2.719 & 3.393 & 3.467 \\
\hline BS-05 & 0.00787 & 2.626 & 3.473 & 1.706 & 3.459 & 2.578 & 3.368 & 3.459 \\
\hline BS-06 & 0.00827 & 2.985 & 3.471 & 1.663 & 3.457 & 2.544 & 3.361 & 3.457 \\
\hline BS-07 & 0.01137 & 2.196 & 3.461 & 1.389 & 3.441 & 2.306 & 3.310 & 3.441 \\
\hline BS-08 & 0.01242 & 2.074 & 3.457 & 1.316 & 3.436 & 2.235 & 3.293 & 3.436 \\
\hline BS-09 & 0.01373 & 2.772 & 3.442 & 1.235 & 3.429 & 2.152 & 3.272 & 3.429 \\
\hline BS- 10 & 0.01878 & 2.465 & 3.435 & 0.997 & 3.403 & 1.882 & 3.192 & 3.403 \\
\hline BS-11 & 0.01917 & 2.374 & 3.433 & 0.983 & 3.401 & 1.864 & 3.186 & 3.401 \\
\hline BS-12 & 0.04569 & 2.195 & 3.337 & 0.481 & 3.262 & 1.097 & 2.798 & 3.268 \\
\hline BS-13 & 0.05221 & 2.542 & 3.319 & 0.439 & 3.236 & 1.016 & 2.710 & 3.236 \\
\hline BS-14 & 0.08724 & 2.254 & 3.197 & 0.277 & 3.066 & 0.675 & 2.282 & 3.066 \\
\hline BS-15 & 0.09432 & 2.003 & 3.172 & 0.257 & 3.032 & 0.631 & 2.204 & 3.032 \\
\hline
\end{tabular}

of basalt rocks by increasing porosity in our samples is in agreement with the results obtained by Robertson et al. (1974) [41].

Experimental results are compared with the empirical models (equations (7)-(11)), as shown in Figures 2 and 4. Results show that measured data lie well within the theoretical and empirical bounds that prove the authenticity of obtained experimental results, whereas the values of the exponents/coefficients in empirical models mentioned in Section 2 are calculated by regression analysis using known values of experimental thermal conductivity $\left(\lambda_{\exp }\right)$, fractional porosity $(\phi)$, solid matrix thermal conductivity $\left(\lambda_{\mathrm{s}}\right)$, and saturated fluid (air) thermal conductivity $\left(\lambda_{\mathrm{f}}\right)$ for the samples numbered as BS-04, BS-07, BS-08, BS-12, BS-13, BS14, and BS-15. For Asaad's model, the value of empirical exponent $c$ is found to be 4.8; for Zeb et al. model, the value of $m$ is set to be 0.22 ; for EDT model, the value of $z$ is 0.18 ; for Pande and Chaudhary model, the value of $F$ is 2.626; and for Veerendra and Chaudhary model, the value of $\Psi$ is $0.25 \mathrm{Wm}^{-1} \cdot \mathrm{K}^{-1}$.

Using the said calculated values of $c, \mathrm{~m}, z$, and so on along with the values of $\lambda_{\mathrm{s}}, \lambda_{\mathrm{f}}$, and $\phi$ in the abovementioned models (equations (7)-(11)), the effective thermal conductivity values for the remaining eight samples, numbered as BS-01, BS-02, BS-03, BS-05, BS-06, BS-09, BS-10, and BS-11, are calculated. Experimental values of the eight samples are compared with the results obtained through empirical models (given in Table 5) and are shown in Figure 4. The fractional porosity in Figure 4 is restricted between 0 and 0.02 ; this is because of the fact that the samples having fractional porosities ranging from 0.02 to 0.1 are used to estimate the effective thermal conductivity of the other samples having lower fractional porosity values. On the other hand, if all the fifteen samples were used for the calculation of adjustable parameters and their exponents for prediction, then it will result just a curve fitting and will not provide a true theoretical model.

Results in Figure 4 show that the thermal conductivity decreases with the increase in the porosity and experimental results deviate more from the mixing law model

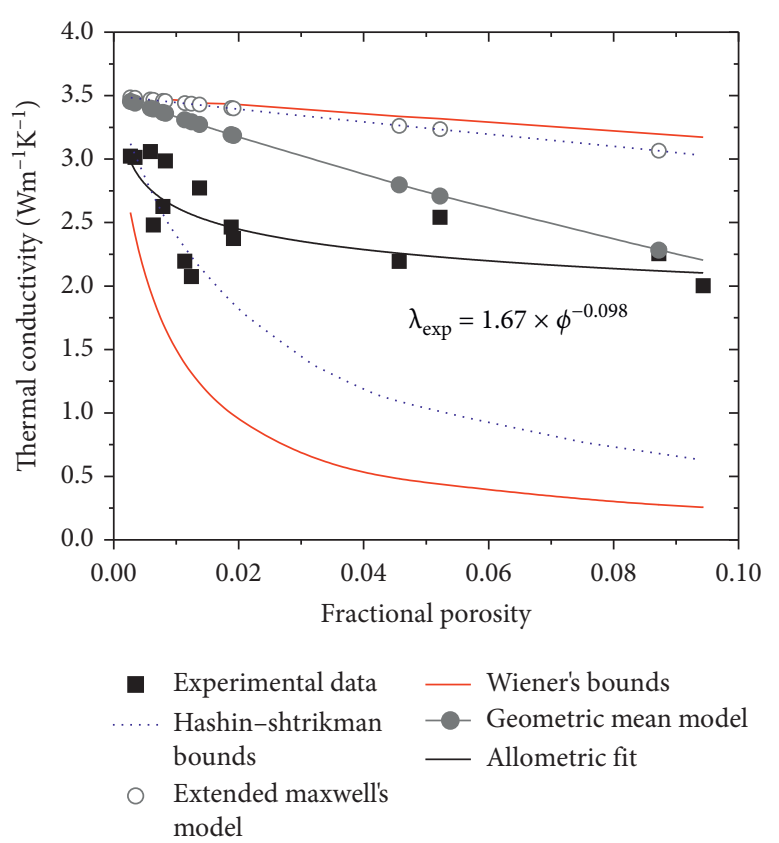

Figure 2: Comparison of experimental thermal conductivity with the values predicted by mixing law models along with Wiener's and $\mathrm{H}-\mathrm{S}$ bounds.

data as the fractional porosity increases from $0.8 \%$. It has been observed that the results predicted by empirical models are better than the results obtained through mixing law models. One of the main reasons for getting better results with the empirical models might be the use of suitable parameters in these models that makes them more effective as compared to theoretical models.

\section{Conclusion}

In this study, thermal transport properties of fifteen consolidated igneous basalt rocks are measured using Gustafsson's probe technique under ambient conditions. All the samples are obtained from the place Warsak, about $30 \mathrm{~km}$ 


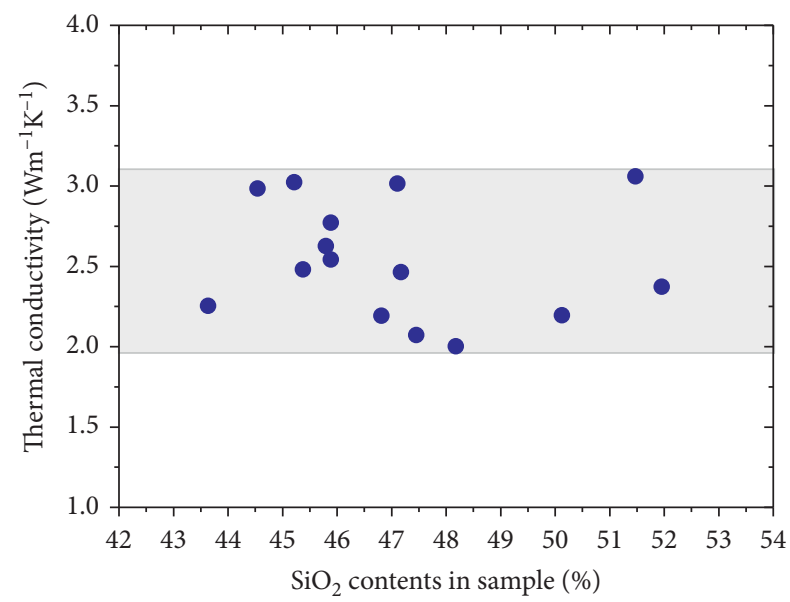

Figure 3: Change in thermal conductivity of basalt samples with the change in silica contents $\left(\mathrm{SiO}_{2}\right)$.

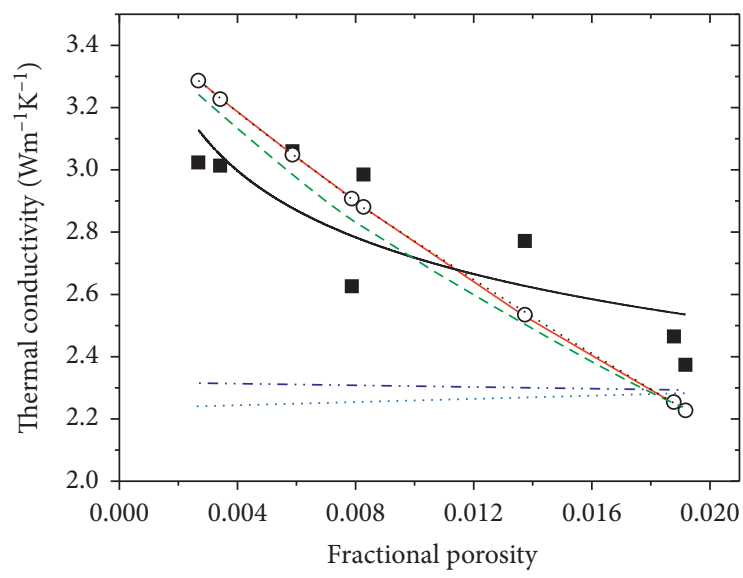

- Experimental data

Veerendra and Chaudhary model (equation.08)

- - - Zeb and Maqsood model (equation.10)

— Asaad's model (equation.07)

.... Pande and Chaudhary model (equation.09)

o. Exponential decay model (equation.11)

Figure 4: Comparison of experimental and empirical model thermal conductivities of the basalt samples as the function of fractional porosity.

TABLE 5: A comparison of the measured experimental thermal conductivity and the effective thermal conductivity calculated according to different empirical models for basalt samples.

\begin{tabular}{|c|c|c|c|c|c|c|c|c|c|c|c|c|}
\hline \multirow[t]{3}{*}{ Sample number } & \multirow[t]{3}{*}{ Fractional porosity } & \multirow[t]{3}{*}{$\lambda_{\exp }\left(\mathrm{Wm}^{-1} \cdot \mathrm{K}^{-1}\right)$} & Asaac & model & \multicolumn{2}{|c|}{$\begin{array}{l}\text { Veerendra } \\
\text { and } \\
\text { Chaudhary } \\
\text { model }\end{array}$} & \multicolumn{2}{|c|}{$\begin{array}{l}\text { Pande and } \\
\text { Chaudhary } \\
\text { model }\end{array}$} & \multicolumn{2}{|c|}{$\begin{array}{l}\text { Zeb et al. } \\
\text { model }\end{array}$} & \multicolumn{2}{|c|}{ EDT model } \\
\hline & & & \multicolumn{2}{|c|}{ Equation (7) } & \multicolumn{2}{|c|}{ Equation (8) } & \multicolumn{2}{|c|}{ Equation (9) } & \multicolumn{2}{|c|}{ Equation (10) } & \multicolumn{2}{|c|}{ Equation (11) } \\
\hline & & & $\lambda_{\mathrm{e}}$ & $\% \mathrm{dev}$ & $\lambda_{\mathrm{e}}$ & $\% \mathrm{dev}$ & $\lambda_{\mathrm{e}}$ & $\% \mathrm{dev}$ & $\lambda_{\mathrm{e}}$ & $\% \mathrm{dev}$ & $\lambda_{\mathrm{e}}$ & $\% \mathrm{dev}$ \\
\hline BS-01 & 0.0027 & 3.02 & 3.29 & -8.00 & 2.24 & 34.88 & 2.32 & 30.57 & 3.24 & -6.78 & 3.29 & -8.00 \\
\hline BS-02 & 0.0034 & 3.01 & 3.23 & -6.69 & 2.24 & 34.31 & 2.32 & 30.19 & 3.18 & -5.10 & 3.23 & -6.60 \\
\hline BS-03 & 0.0059 & 3.06 & 3.05 & 0.36 & 2.25 & 36.06 & 2.31 & 32.35 & 2.98 & 2.55 & 3.05 & 0.36 \\
\hline BS-05 & 0.0079 & 2.63 & 2.91 & -9.71 & 2.25 & 16.50 & 2.31 & 13.73 & 2.84 & -7.54 & 2.91 & -9.70 \\
\hline BS-06 & 0.0083 & 2.99 & 2.88 & 3.61 & 2.26 & 32.37 & 2.31 & 29.28 & 2.81 & 6.08 & 2.88 & 3.61 \\
\hline BS-09 & 0.0137 & 2.77 & 2.53 & 9.41 & 2.27 & 22.22 & 2.30 & 20.42 & 2.49 & 11.19 & 2.54 & 9.35 \\
\hline BS-10 & 0.0188 & 2.47 & 2.25 & 9.57 & 2.28 & 8.11 & 2.30 & 7.36 & 2.26 & 9.26 & 2.25 & 9.36 \\
\hline BS-11 & 0.0192 & 2.37 & 2.23 & 6.49 & 2.28 & 4.08 & 2.30 & 3.44 & 2.24 & 6.22 & 2.23 & 6.55 \\
\hline
\end{tabular}


from Peshawar city in Pakistan. ASTM methods are applied to find the density-related parameters, whereas mineral composition of the samples is studied using XRF technique. Experimentally determined values of thermal conductivity and thermal diffusivity for basalt rocks are found in between 2.003 and $3.024 \mathrm{Wm}^{-1} \mathrm{~K}^{-1}$ and 0.825 to $1.250 \mathrm{~mm}^{2} \mathrm{~s}^{-1}$, respectively, whereas volumetric heat capacity ranges from 2.338 to $2.682 \mathrm{MJm}^{-3} \cdot \mathrm{K}^{-1}$. It has been observed that the thermal conductivity of the studies basalt samples decreases with the increase in porosity values; however, no clear trend can be seen from the obtained results. Furthermore, the thermal conductivity of the samples is also predicted using theoretical and mixing law models. The predicted results are compared with the experimental values and the corresponding deviations are reported. The deviation of predicted results from the actual experimental results may be because of not including many factors like size and number of pores, pore connectivity, grain sizes, and tortuosity. It has been observed that the results predicted by empirical models are better than the results obtained through mixing law models. In the mixing law models, rather simplified geometries of materials are considered as compared to the empirical models. One of the main reasons for getting better results with the empirical models might be the use of suitable parameters in these models which makes them more effective as compared to mixing law models. This study can be further extended by including realistic pore-grain structure and lithology of the rock.

\section{Abbreviations}

TPS: Transient Plane Source

ASTM: American Society of Testing and Materials

XRF: X-ray fluorescence

WAM: Weighted arithmetic mean

WHM: Weighted harmonic mean

WGM: Weighted geometric mean

EDT: Exponential decay trial

H-S: Hashin and Shtrikman

SD: $\quad$ Standard deviation

F: $\quad$ Empirical coefficient for Pande and Chaudhary model

$c: \quad$ Empirical exponent for Asaad's equation

$m$ : Empirical coefficient for Zeb et al. model

$z$ : $\quad$ Empirical exponent

F: $\quad$ Felsic-mafic index

B: Bulk density

$c_{\mathrm{p}}$ : $\quad$ Specific heat at constant pressure.

Greek symbols

$\phi$ : Fractional porosity

$\Psi$ : Adjustable parameter for Veerendra and Chaudhary model

$\alpha$ : Thermal diffusivity

$\lambda$ : Thermal conductivity

$\lambda_{\mathrm{f}}$ : Thermal conductivity of fluid phase

$\lambda_{\mathrm{s}}$ : Thermal conductivity of solid phase

$\rho$ : $\quad$ Mass density

$\lambda_{\text {eff }}$ : Effective thermal conductivity

$\lambda_{\mathrm{e}}$ : Experimental thermal conductivity.

\section{Data Availability}

All the data used to support this study are included within the article.

\section{Conflicts of Interest}

The authors declare that they have no conflicts of interest.

\section{References}

[1] A. M. Aurangzeb and A. Maqsood, "Modeling of the effective thermal conductivity of consolidated porous media with different saturants: a test case of Gabbro rocks," International Journal of Thermophysics, vol. 28, no. 4, pp. 1371-1386, 2007.

[2] L. Rybach, "Thermal properties and temperature-related behavior of rock/fluid systems," Journal of Volcanology and Geothermal Research, vol. 56, no. 1-2, pp. 171-172, 1993.

[3] M. G. Davis, D. S. Chapman, T. M. Van Wagoner, and P. A. Armstrong, "Thermal conductivity anisotropy of metasedimentary and igneous rocks," Journal of Geophysical Research: Solid Earth, vol. 112, 2007.

[4] E. Balkan, K. Erkan, and M. Şalk, "Thermal conductivity of major rock types in western and central Anatolia regions, Turkey," Journal of Geophysics and Engineering, vol. 14, no. 4, pp. 909-919, 2017.

[5] W. Woodside and J. H. Messmer, "Thermal conductivity of porous media. II. Consolidated rocks," Journal of Applied Physics, vol. 32, no. 9, pp. 1699-1706, 1961.

[6] R. W. Zimmerman, "Thermal conductivity of fluid-saturated rocks," Journal of Petroleum Science and Engineering, vol. 3, no. 3, pp. 219-227, 1989.

[7] J. Anand, W. H. Somerton, and E. Gomaa, "Predicting thermal conductivities of formations from other known properties," Society of Petroleum Engineers Journal, vol. 13, no. 5, pp. 267-273, 1973.

[8] S. Fuchs, F. Schütz, H. J. Förster, and A. Förster, "Evaluation of common mixing models for calculating bulk thermal conductivity of sedimentary rocks: correction charts and new conversion equations," Geothermics, vol. 47, pp. 40-52, 2013.

[9] M. Abid, U. Hammerschmidt, and J. Köhler, "Temperature and moisture dependent thermophysical properties of Sander sandstone," International Journal of Thermal Sciences, vol. 86, pp. 88-94, 2014.

[10] A. Bishop, C. Klein, and C. S. Hurlbut Jr., "Manual of Mineralogy (after James D. Dana) 21st Edition," Mineralogical Magazine, vol. 58, no. 392, pp. 524-526, 1993.

[11] V. Cermak and L. Rybach, "Thermal conductivity and specific heat of minerals and rocks," in Landolt-Börnstein - Group V GeophysicsSpringer-Verlag, Berlin, Germany, 1982.

[12] J. Sim, C. Park, and D. Y. Moon, "Characteristics of basalt fiber as a strengthening material for concrete structures," Composites Part B: Engineering, vol. 36, no. 6-7, pp. 504-512, 2005.

[13] E. Quagliarini, F. Monni, S. Lenci, and F. Bondioli, “Tensile characterization of basalt fiber rods and ropes: a first contribution," Construction and Building Materials, vol. 34, pp. 372-380, 2012.

[14] A. Bouguerra, A. Aït-Mokhtar, O. Amiri, and M. B. Diop, "Measurement of thermal conductivity, thermal diffusivity and heat capacity of highly porous building materials using transient plane source technique," International Communications in Heat and Mass Transfer, vol. 28, no. 8, pp. 10651078, 2001. 
[15] A. Bouguerra, J. P. Laurent, M. S. Goual, and M. Queneudec, "The measurement of the thermal conductivity of solid aggregates using the transient plane source technique," Journal of Physics D: Applied Physics, vol. 30, no. 20, pp. 2900-2904, 1997.

[16] C. Gruescu, A. Giraud, F. Homand, D. Kondo, and D. P. Do, "Effective thermal conductivity of partially saturated porous rocks," International Journal of Solids and Structures, vol. 44, no. 3-4, pp. 811-833, 2007.

[17] L. Gong, Y. Wang, X. Cheng, R. Zhang, and H. Zhang, "Porous mullite ceramics with low thermal conductivity prepared by foaming and starch consolidation," Journal of Porous Materials, vol. 21, no. 1, pp. 15-21, 2014.

[18] I. U. M Ahmad, K. S. S. Ali, B. Khan, and M. A. Shah, "The geology of the Warsak area, Peshawar, west Pakistan," Geological Bulletin, University of Peshawar, vol. 4, pp. 44-78, 1969.

[19] D. R. C. Kempe, "Acicular hornblende schists and associated metabasic rocks from North-West Pakistan," Mineralogical Magazine, vol. 42, no. 323, pp. 405-406, 1978.

[20] U. B. S. C. R. Meissner, M. Hussain, and M. A. Rashid, Geology of the Parachinar Quadrangle, Pakistan, United States Department of the Interior, Geological Survey, Washington, DC, USA, 1975.

[21] D. R. C. Kempe, "The petrology of the Warsak alkaline granites, Pakistan, and their relationship to other alkaline rocks of the region," Geological Magazine, vol. 110, no. 5, pp. 385-404, 1973.

[22] M. Qasim Jan and A. Karim, “Continental magmatism related to late paleozoic-early mesozoic rifting in northern Pakistan and kashmir," Geological Bulletin, University of Peshawar, vol. 23, pp. 1-25, 1990.

[23] W. H. Somerton, Thermal Properties and Temperature Related Behaviour of Rock/Fluid Systems, Elsevier, Amsterdam, Netherlands, 1992.

[24] Z. Hashin and S. Shtrikman, "A variational approach to the theory of the effective magnetic permeability of multiphase materials," Journal of Applied Physics, vol. 33, no. 10, pp. 3125-3131, 1962.

[25] W. Woodside and J. H. Messmer, "Thermal conductivity of porous media. I. Unconsolidated sands," Journal of Applied Physics, vol. 32, no. 9, pp. 1688-1699, 1961.

[26] A. E. Beck, "An improved method of computing the thermal conductivity of fluid-filled sedimentary rocks," Geophysics, vol. 41, no. 1, pp. 133-144, 1976.

[27] Y. Asaad, A Study of the Thermal Conductivity of FluidBearing Porous Rocks, University of California, Berkeley, CA, USA, 1955.

[28] S. Edrisi, N. K. Bidhendi, and M. Haghighi, "A new approach to modeling the effective thermal conductivity of ceramics porous media using a generalized self-consistent method," Heat and Mass Transfer, vol. 53, no. 1, pp. 321-330, 2017.

[29] V. Kumar and D. R. Chaudhary, "Prediction of effective thermal conductivity of two-phase porous materials using resistor model," Indian Journal of Pure \& Applied Physics, vol. 18, pp. 984-987, 1980.

[30] M. S. Goual, A. Bali, and M. Quéneudec, "Effective thermal conductivity of clayey aerated concrete in the dry state: experimental results and modelling," Journal of Physics D: Applied Physics, vol. 32, no. 23, pp. 3041-3046, 1999.

[31] R. N. Pande, V. Kumar, and D. R. Chaudhary, "Thermal conduction in a homogeneous two-phase system," Pramana, vol. 22, no. 1, pp. 63-70, 1984.

[32] A. Aurangzeb, Z. Ali, S. F. Gurmani, and A. Maqsood, "Simultaneous measurement of thermal conductivity, thermal diffusivity and prediction of effective thermal conductivity of porous consolidated igneous rocks at room temperature," Journal of Physics D: Applied Physics, vol. 39, no. 17, pp. 3876-3881, 2006.

[33] S. E. Gustafsson, "Transient plane source techniques for thermal conductivity and thermal diffusivity measurements of solid materials," Review of Scientific Instruments, vol. 62, no. 3 , pp. 797-804, 1991.

[34] C. Dixon, M. R. Strong, and S. M. Zhang, "Transient plane source technique for measuring thermal properties of silicone materials used in electronic assemblies," The International Journal of Microcircuits and Electronic Packaging, vol. 23, no. $4,2000$.

[35] M. Anis-ur-Rehman and A. Maqsood, "Measurement of thermal transport properties with an improved transient plane source technique," International Journal of Thermophysics, vol. 24, no. 3, pp. 867-883, 2003.

[36] A. Zeb, T. Firdous, and A. Maqsood, "Thermophysical properties of dunite rocks as a function of temperature along with the prediction of effective thermal conductivity," Natural Science, vol. 2, no. 6, pp. 626-630, 2010.

[37] R. Le Maitre, A. Streckeisen, B. Zanettin, M. J. Le Bas et al., Igneous Rocks: A Classification and Glossary of Terms (Recommendations of the IUGS Subcommission on the Systematics of Igneous Rocks), Cambridge University Press, Cambridge, UK, 2002.

[38] ASTM, Standard Test Method for Specific Gravity and Absorption of Rock for Erosion Control-standard D6473-15, ASTM, West Conshohocken, PA, USA, 2015.

[39] A. Maqsood, M. Anis-ur-Rehman, and I. H. Gul, "Chemical composition, density, specific gravity, apparent porosity, and thermal transport properties of volcanic rocks in the temperature range 253 to $333 \mathrm{~K}$," Journal of Chemical \& Engineering Data, vol. 48, no. 5, pp. 1310-1314, 2003.

[40] T. Y. Roy RF and A. E. Beck, "Thermophysical properties of rocks," "Thermophysical properties of rocks," in Physical Properties of Rocks and Minerals, Y. S. Touloukian, W. R. Judd, and R. F. Roy, Eds., McGraw-Hill, New York, NY, USA, 1981.

[41] E. C. Robertson and D. L. Peck, "Thermal conductivity of vesicular basalt from Hawaii," Journal of Geophysical Research, vol. 79, no. 32, pp. 4875-4888, 1974. 